Biotechnology, where to next?

\title{
Richard Pearson
}

Facilities for postgraduate training in the United Kingdom must be maintained in order to meet the steady demand for postdocs in biotechnology.

IN the late 1970 s and early 1980 s biotechnology was the glamour technology attracting many millions of pounds from venture capitalists and governments alike. Since then some of the glamour has gone, as have some of the jobs, as several of the new venture capital companies have declared redundancies and others have been taken over by the established multinationals. What is clear is that the payback period for this technology is going to be considerably longer than for microelectronics for instance, stretching into the next centruy. Initially, the Western world, and especially the United States, the United Kingdom and West Germany, was ahead of Japan in this new technology, building on its historically more developed basic scientific research. However, in the past five years Japan has caught up fast and now has a considerable amount of expertise in molecular biology. It has several large research groups augmented by large numbers of postgraduate research students, often as many as 25 per professor. Government funding of academic research is now substantial and large collaborative programmes between universities and industrial laboratories are thriving, often with extensive public financial support.

One of the keys to success in the new technologies is the availability of skilled personnel, and in the case of biotechnology much of this is at the postdoctoral level. In this respect the United Kingdom has been a world leader. The UK Science and Engineering Research Council (SERC) has a key role in biotechnology, supporting research and postgraduate training and encouraging joint ventures between industry and higher education. SERC has just published a report ${ }^{1}$ monitoring trends in the supply and demand for key skills. Since 1983 it has been estimated that the total number of professional technical staff in biotechnology has grown by two-thirds to a total of about 3,500 in 1986. This increase has been largely due to expansion in research centres and higher education, primarily at postdoctoral level and involving staff on short-term contracts. The growth in joint ventures is increasingly blurring the dividing lines between industry, research institutes and higher education, as academic bodies set up industrial service companies, research centres become major sources of research students and postdoctoral training, and industry becomes actively involved in higher education. Nevertheless there are still many sectoral differences.

In the industrial sector the number of companies has doubled since 1983 to 100 , fuelled by new start-ups and established companies moving into novel biotechnology. The main emphasis remains heavily focused on research and development. However, production, plant engineering and industrial service companies are developing, although it is likely to be some years before they have significant employment levels. The majority of companies are, however, still small, half employing less than ten professional staff but with a few major companies accounting for half of the 1,600 in this sector. Among the 20 or so research centres employing

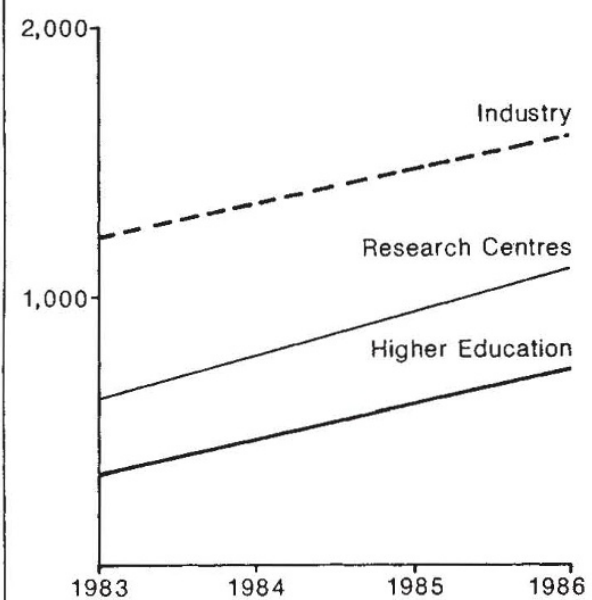
Changes in employment of personnel in biotechnology for the years 1983-1986 (from ref. 1).

about another 1,000 staff, there was a greater concentration of employment with five employing 100 or more such staff. Finally, there are more than 120 university, polytechnic and medical school departments active in novel biotechnology, employing a further 700 professionals - a doubling since 1983 and the fastest rate of growth in the three sectors (see graph).

Biotechnology is an interdisciplinary activity involving scientists and technologists in a range of bioscience and bioprocess skills that cut across conventional academic boundaries. Nowadays they can best be classified under three broad skill groups: genetic engineering (the fastest growing group), hybridoma technology, and bioprocess technology. In qualification terms the emphasis remains on $\mathrm{PhD}$ and postdoctoral levels, the only exception being the biochemical engineers, where industrial companies recruit a few specialist MSc graduates to work with large-scale reactors. First degree gradu- ates have only been in demand as scientific assistants or higher-level technicians. Although employment has expanded significantly, recruitment to individual organizations has typically been measured in ones or twos each year, with only seven industrial firms and two research institutes recruiting ten or more such people in the past year. Recruitment difficulties for industry and research centres have been largely confined to highly specialist posts, usually at senior level, where the quality rather than the quantity of applicants was the problem.

The main recruitment problems have been experienced in higher education where the problems were being compounded by the vacancies only offering short-term contracts and relatively low salaries combined with generally poor facilities and low morale. The study found that the brain drain in biotechnology had in fact lessened and was now principally focused on younger scientists for whom few opportunities existed in higher education, and with the growth in demand in industry offering more opportunities in the UK for experienced people. The slowdown in growth and the maturing of biotechnology in North America has also been reducing the demand for migrants.

Looking ahead, there will be further growth in demand, although it is likely to be dominated by short-term posts in research centres and higher education. Selected shortages are likely to continue and become more widespread, particularly in relation to skills in plant molecular biology and in aspects of bioprocess technology. The most important factor is likely to be public expenditure, which on the one hand may boost demand but on the other may not keep pace with the growing need for postgraduate training, especially the need for increased levels of supervisory time and the associated equipment costs. At present, skill shortages primarily affect higher education, and if this remains the case then it will not be too long before they feed through and affect the research centres and industry alike and act as a serious constraint on the United Kingdom's development of biotechnology.

Richard Pearson is at the Institute of Manpower Studies, Mantell Building, University of Sussex, Brighton BN1 9RF, UK

1. Bevan, S., Parsons, D. \& Pearson, R. Monitoring the Biotechnology Labour Market (Science and Engineering Research Council, 1987). 